\title{
Sobre (in)coerências entre a Universidade Pública e Popular, a Engenharia e o desenvolvimento de Tecnologias Sociais
}

\author{
On the (in)coherences of the relation between public and popular \\ university, the engineering area and the development of social \\ technologies \\ Leandro Bordin \\ Universidade Federal da Fronteira Sul \\ lbordin@uffs.edu.br \\ Walter Antonio Bazzo \\ Universidade Federal de Santa Catarina \\ walter.bazzo@ufsc.br
}

\section{Resumo}

Com o objetivo de destacar os encontros e desencontros entre a proposta de universidade pública e popular com o desenvolvimento de Tecnologias Sociais (TS), o presente artigo explicita os resultados das análises feitas nos ordenamentos institucionais da Universidade Federal da Fronteira Sul (UFFS) e, principalmente, nos Projetos Pedagógicos dos cinco cursos de Engenharia por ela ofertados. A metodologia de análise documental foi desenvolvida tendo como mote as seguintes categorias: (a) justificativa para criação do curso, (b) perfil do egresso e objetivos do curso e (c) organização curricular. Os resultados indicam que, apesar de a UFFS ter forte vinculação com movimentos sociais e se projetar como desenvolvedora de TS, há uma considerável falta de clareza sobre o que seja conceber um curso de Engenharia nessa perspectiva. Apesar de haver algumas importantes iniciativas, os documentos revelam um longo caminho a ser percorrido na superação de modelos formativos historicamente consolidados.

Palavras-chave: Ensino da tecnologia. Tecnologia da Engenharia.

Desenvolvimento integrado.

\section{Abstract}

This article explains the results of analyses conducted within the institutional frameworks of Universidade Federal da Fronteira Sul (UFFS) and in particular in the Pedagogical Projects of its five Engineering courses to highlight the positive and negative points concerning the relation between the proposal for a public and popular university and the development of Social Technologies (TS). The documentary analysis methodology was conducted using the following categories: (a) reason for creating the course, (b) profile of the graduate and course objectives, and (c) curriculum framework. Despite UFFS having strong bonds with social movements and being acknowledged as a TS developer, the 
ISSN: 2446-774X

results indicate that there is a considerable lack of clarity concerning how to design an Engineering course on this basis. Despite some important initiatives, the documents reveal there is a long way to go in overcoming historically consolidated formative templates.

Key words: Technology teaching. Engineering Technology. Integrated development.

\section{Introdução: a educação em Engenharia}

A educação em Engenharia vem sendo problematizada em trabalhos que, com diferentes abordagens teórico-metodológicas e com foco de investigação em distintos cenários educativos, objetivam pela via da educação desconstruir a crença de que a tecnologia é neutra, autônoma, determinista e benfeitora em sua totalidade. Destacamos aqui as teses de doutorado de Bazzo (1998), Lisingen (2002), Menestrina (2008), Carletto (2009) e Jacinski (2012) e a dissertação de mestrado de Fraga (2007), as quais têm como elemento balizador o referencial proporcionado pelos estudos CTS - Ciência, Tecnologia e Sociedade. As pesquisas, reflexões e proposições dos referidos autores têm pensado o processo formativo em Engenharia na estreita relação entre questões técnicas, sociais e humanas.

Considerando essa estreita relação - sociotécnica - corroboramos os questionamentos feitos pelos referidos autores no que concerne à, ainda, forte concepção de que na formação do profissional de Engenharia pouco importa discutir questões que extrapolem o caráter puramente técnico da profissão. Os trabalhos mencionados dão conta de revelar a fragilidade dos cursos de Engenharia frente as promissoras possibilidades que um currículo articulado em torno do enfoque CTS poderia oferecer aos nossos estudantes. Nessa nova configuração entrariam em cena conteúdos - sociotécnicos - importantes que ajudariam no entendimento das tantas variáveis que precisam ser equalizadas no entendimento dos problemas de Engenharia e na proposição de soluções tecnológicas.

Destacamos, nesse ponto, a urgente necessidade de, na condição de engenheiros educadores, (re)pensarmos a formação 'engessada' que a maioria dos cursos de Engenharia proporciona aos jovens brasileiros: currículos inchados, compartimentados e sedimentados, que estimulam a retórica de que o bom profissional é aquele que sabe ser inovador, 'agressivo' e competitivo no 'mercado' de trabalho. Sim, ainda temos, infelizmente, muita dificuldade em efetivar uma formação para o 'mundo' do trabalho.

Precisamos enfaticamente problematizar a formação para o 'mercado' tão presente nas escolas de Engenharia. Quantos movimentos serão necessários para romper com esse padrão empresarial e, também, dos órgãos de classe que, muitas vezes, ditam o tipo de formação na medida em que criam regras e barreiras à habilitação profissional? O que, de fato, tem valor para esse 'mercado'? Quais interesses e concepções estão por trás desse tipo de decisão? 


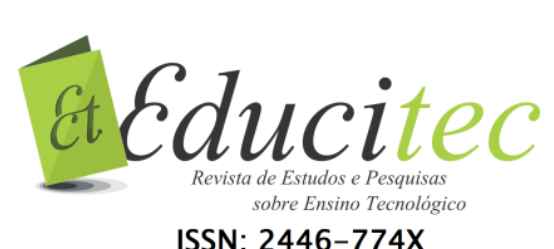

Tais questionamentos nos remetem à reflexão acerca da autonomia dos educadores para alterar os rumos da formação em Engenharia.

Nesse sentido, é importante sempre ter em pauta como os cenários econômicos, políticos, sociais e culturais contribuíram historicamente e ainda contribuem (ou não) para o desenvolvimento da ciência e da tecnologia e direcionaram suas práticas em termos, inclusive, de educação. Igualmente importante é perceber e refletir como a educação tecnológica ainda é fortemente atrelada ao desenvolvimento econômico e aos processos de modernização, de maneira a atender, via de regra, as demandas impostas pelo modo de produção capitalista.

Diante dos inúmeros e multifacetados problemas que assolam o Brasil - e o mundo - defendemos que a educação em Engenharia precisa avançar na formação de cidadãos que atuem com clareza, discernimento e consciência nos mais diferentes âmbitos do desenvolvimento sociotécnico do nosso país. Afinal, negligenciar na formação e no trabalho dos profissionais de Engenharia os aspectos políticos, econômicos, sociais e ambientais inerentes à condição humana é caminhar na direção de um futuro nada promissor.

É urgente que os engenheiros e engenheiras das diferentes especialidades (re)signifiquem seus papéis e responsabilidades frente as inúmeras facetas do desenvolvimento social. Como mencionado, a relação é simbiótica e, portanto, discutir a tecnologia pela tecnologia parece não fazer mais sentido diante da necessidade de formar seres humanos mais sensíveis e atuantes na resolução dos problemas coletivos.

Postman e Weingartner (1971), há mais de quatro décadas escreveram sobre uma nova fórmula de ensino que se mantém bastante atual. Considerando os atuais moldes da educação em Engenharia, então, é possível extrair inúmeras lições. De forma totalmente alinhada com as discussões aqui levantadas, os autores partem dos pressupostos de que (1) a sobrevivência da sociedade está ameaçada por um número crescente de problemas inéditos e, até a data, insolúveis e (2) alguma coisa poderá ser feita para melhorar a situação. A aposta, para uma possível mudança, é numa nova abordagem de educação. Os autores acreditam no aperfeiçoamento da condição humana por meio de uma educação mais reflexiva, crítica, libertadora, humanitária, contextualizada e comprometida com os problemas coletivos.

Trabalhar com o argumento de que "a mudança - constante, acelerada, ubíqua - é a característica mais impressionante do mundo em que vivemos e que o nosso sistema educacional ainda não reconheceu isso" é reconhecer que a educação em Engenharia, da forma tradicional como se apresenta, oferece poucas oportunidades para que os futuros engenheiros e engenheiras estejam sensíveis e conscientes da realidade - sociotécnica - que os cerca (POSTMAN; WEINGARTNER, 1971, p. 16).

Fraga, Novaes e Dagnino (2010), Bazzo (2014) e Lisingen (2015) apostam que uma 'nova' educação em Engenharia não passa pelo simples fato de acrescentar no currículo disciplinas da área de humanidades. Para os autores, a raiz da questão centra-se em mudanças epistemológicas acerca, principalmente, da neutralidade da tecnociência. "Alavancar uma sociedade alternativa, baseada 


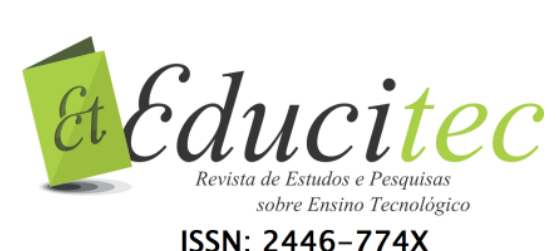

ISSN: $2446-774 X$

em outros valores, interesses e atores, exige do engenheiro uma reflexão profunda sobre a não neutralidade da tecnociência e a relação que esta tem com as forças que estruturam a sociedade" (FRAGA; NOVAES; DAGNINO, 2010, p. 232).

Para os autores supracitados, a formação em Engenharia deve procurar dar respostas coerentes e justas aos problemas colocados pela sociedade. Nessa direção, mais uma vez defendemos que a dinâmica formativa proporcionada por um currículo articulado em torno da relação CTS se apresenta como uma coerente alternativa frente aos tradicionais modelos educativos.

Postman e Weingartner (1971) apostam numa educação mais significativa, questionadora, calcada na resolução de problemas e com práticas interdisciplinares. Os autores (1971, p. 111) defendem que é preciso deixar de lado a expressão "não fugir da matéria" e abrir espaço para discussões que expandam a consciência crítica do estudante. Ou seja, deve-se proporcionar diálogos autênticos e relevantes e trocas de experiências que efetivamente construam uma base sólida de conhecimentos sociotécnicos. No encontro disso, Nóvoa (2017, p. 1), ao falar sobre a necessidade de compreendermos a educação pública como compromisso social, nos inspira a pensar que fugir da matéria é, em boa medida, ter a consciência de que "não resolvemos nossos problemas se não resolvermos o problema dos outros".

Uma vez que os argumentos até aqui construídos destacam a necessidade de investirmos esforços em mudanças conceituais e epistemológicas acerca do objeto de trabalho da Engenharia - a tecnologia -, precisamos, então, provocar a desconstrução do modelo de desenvolvimento tecnológico hegemônico que valoriza a promoção de Tecnologias Convencionais (TC), também denominadas de Tecnologias Capitalistas.

Nesse contexto, o objetivo do presente trabalho é analisar de que forma o projeto de universidade e de curso de Engenharia projetados pela Universidade Federal da Fronteira Sul se articulam com o desenvolvimento de tecnologias contrahegemônicas, denominadas de Tecnologias Sociais (TS). A escolha do lócus de investigação, como veremos mais detalhadamente no decorrer do texto, se deve ao fato de a UFFS ter uma expressiva participação de movimentos sociais nos processos de criação, implantação e consolidação da universidade, o que a projeta como desenvolvedora de tecnologias socialmente relevantes na/para sua região de abrangência.

Os resultados e discussões são provenientes da pesquisa documental realizada nos ordenamentos institucionais da UFFS e, principalmente, nos Projetos Pedagógicos dos cinco cursos de Engenharia por ela ofertados.

\section{A Engenharia e o desenvolvimento de Tecnologias Sociais}

Ancorada na ideia de progresso e prosperidade universal, a Engenharia, via de regra, opera com a (re)produção de modelos tecnológicos cujos produtos e processos obedecem a lógica de um sistema, em grande medida, excludente. Afinal, produzir tecnologias pela e para a empresa privada é alimentar um 


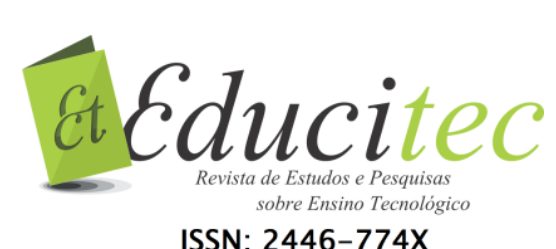

ISSN: $2446-774 X$

sistema no qual as desigualdades são entendidas como um efeito colateral inevitável do 'progresso' tecnológico e do 'crescimento' econômico de uma nação.

A crença neutra e determinista acerca dos dispositivos e processos tecnológicos é tão marcante na sociedade moderna que, apesar das críticas sofridas nos últimos anos, o 'mercado' deu conta de disseminar o jargão da inovação. E os cursos de Engenharia, inclusive respaldados pelas Diretrizes Curriculares Nacionais (DCNs) para o ensino de Engenharia, rapidamente incorporaram a lógica de uma formação para o empreendedorismo e a inovação.

Com forte apelo capitalista a compreensão do que seja uma inovação precisa ser questionada. Afinal, como aponta Winner (1987, p. 49) a inovação precisa ser vista como "um ciclo de ajustes mútuos entre os fatores sociais, culturais e técnicos". Sendo assim, precisamos elevar a inovação tecnológica ao patamar de prioridade social. Isso tem sido feito desde 2003, com a criação da Rede de Tecnologia Social (RTS), por meio da construção e divulgação de experiências em torno do desenvolvimento de Tecnologias Sociais. A Tecnologia Social (TS) surge da preocupação com a crescente exclusão social, e com a precarização e informalização do trabalho e busca redefinir o modelo hegemônico de desenvolvimento tecnológico (DAGNINO, 2009).

A construção do conceito de TS leva em conta duas perspectivas. Na primeira a TS é interpretada como oposição ou negação da TC e na segunda como uma ressignificação ao conceito e ao movimento da Tecnologia Apropriada (TA) disseminado nos anos $70 \mathrm{com} 0$ intuito de propor um estilo alternativo de desenvolvimento tecnológico no âmbito dos países latino-americanos periféricos ao capitalismo (NOVAES; DIAS, 2009).

Especificamente sobre a TA, convém destacar que Novaes e Dias (2009, p. 25) se utilizam das deficiências e das críticas sofridas nos idos dos anos 80 para apontar novos caminhos que direcionem à TS. "Embora centrada no objetivo de desenvolvimento social, sua postura era defensiva, adaptativa e não questionadora das estruturas de poder dominantes no plano internacional e local". O foco da TA esteve voltado mais para o produto do que para o processo e, num momento de ascensão do neoliberalismo, a crença de que a simples ampliação do rol de alternativas tecnológicas poderia alterar significativamente o processo de adoção de novas tecnologias, não conseguiu se materializar e, consequentemente, perdeu força ao longo dos anos vindouros.

Ao propor um novo modelo de desenvolvimento como alternativa às tecnologias convencionais de base capitalista, a TS se fundamenta no compromisso com os movimentos sociais e os empreendimentos solidários, estando, nesse sentido, fortemente relacionada com a realidade das comunidades locais, de forma a responder adequadamente os problemas colocados neste contexto em específico. Sendo assim, fica manifesto que a escala e a apropriação da TS são nitidamente diferentes da proposta pela TC (NOVAES; DIAS, 2009).

Alinhado com o trabalho de Novaes e Dias (2009), que muito mais que perseguir uma definição busca desenvolver argumentos para a construção de um marco analítico-conceitual da TS, Dagnino (2009) nos dá uma importante contribuição 


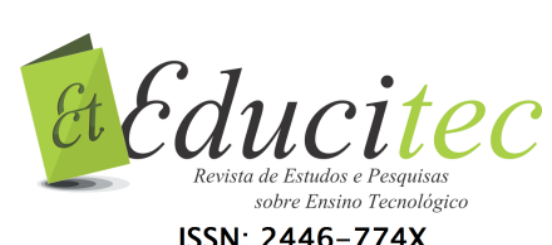

ISSN: $2446-774 X$

na tentativa de materializarmos um conceito acerca do que abarca uma Tecnologia Social. Para o autor, a TS pode ser entendida como:

\begin{abstract}
resultado da ação de um coletivo de produtores sobre um processo de trabalho que, em função de um contexto socioeconômico (que engendra a propriedade coletiva dos meios de produção) e de um acordo social (que legitima o associativismo), os quais ensejam, no ambiente produtivo, um controle (autogestionário) e uma cooperação (de tipo voluntário e participativo), permite uma modificação no produto gerado passível de ser apropriada segundo a decisão do coletivo (DAGNINO, 2009, p. 103).
\end{abstract}

As análises feitas por Dagnino (2009) dão conta de explicar que o que diferencia a TS da TC não é, como muitos consideram, apenas a propriedade dos meios de produção, mas também a forma de controle exercida no e pelo processo tecnológico. É por essa razão, que a TS encontra um profícuo campo de desenvolvimento nos empreendimentos solidários. É onde os elementos-chave da produção - trabalho vivo e trabalho morto - são de propriedade do mesmo ator social. Nesse cenário, não há ator hegemônico - carregado de interesses e valores das mais diferentes ordens - na disputa pela apropriação da tecnologia gerada.

Ao criticar as tecnologias capitalistas, Dagnino (2004, p. 195) destaca o ambiente político e educacional que legitima a perpetuação daquele modelo: "aprendemos na escola de engenharia que, por exemplo, quanto maior a escala de um sistema tecnológico (ou, mais simplesmente, de uma tecnologia), mais eficiente ela será". Nesse sentido, este autor destaca que a efetivação de tecnologias sociais não depende unicamente de uma nova organização do trabalho na perspectiva da economia solidária e da autogestão. É para além disso: há uma forte relação com a forma como se concebe - epistemologicamente - a tecnologia.

"Não é só a maneira como se organiza o trabalho (orgware), mas o substrato tecnológico (hardware e software) e o próprio substrato científico que de alguma maneira produzem a tecnologia que vai ser utilizada na empresa, o que precisa ser transformado" (DAGNINO, 2004, p. 196). Dessa forma, não é suficiente que o empreendimento seja de cooperados e nem que adote um sistema de autogestão. É necessário que disponha de TS, de uma tecnologia, que nesse contexto, não é necessariamente HiTec ou 'de ponta'. Mesmo porque é preciso estar atento para perceber quais concepções a expressão "tecnologia de ponta" carrega nas entrelinhas do discurso empresarial e, infelizmente, educacional. $O$ desenvolvimento tecnológico é, via de regra, apresentado numa "visão mecanicista, linear, determinista e acrítica" (DAGNINO, 2004, p. 199).

\footnotetext{
A ideia de que uma tecnologia tem "ponta" e que outras são "rombudas", de que algumas são altas e outras baixas, busca, na realidade, substituir a noção de que algumas tecnologias são adequadas para determinados fins, e não para outros, e dificultar a percepção de que algumas são funcionais para a reprodução do capital, mesmo que em detrimento de valores morais, ambientais etc. Mas essa concepção ideologizada do fenômeno científico e tecnológico, como tantas outras presentes no cotidiano, é hegemônica e, por isso, muito difícil de contestar (DAGNINO, 2004, p. 200).
} 


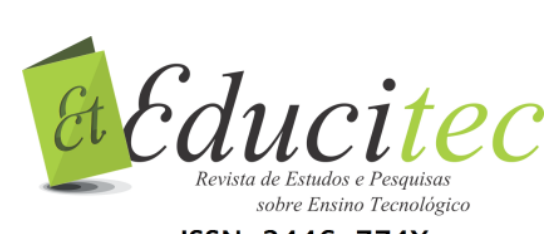

ISSN: 2446-774X

Nessa direção, mais uma vez, o autor (2004, p. 199) denuncia que a universidade reforça a TC, visto que está impregnada no mito da neutralidade da ciência e do determinismo tecnológico: "da mesma forma que a ciência busca a verdade, a tecnologia busca e eficiência". Além disso, a comunidade de pesquisa corrobora o contexto socioeconômico que a envolve. Sendo assim, os padrões sociais, políticos, econômicos e ambientais da sociedade contemporânea enviesam os direcionamentos da Pesquisa e Desenvolvimento (P\&D).

Diante disso, fica evidente a necessidade de avançarmos na geração de uma cultura institucional que viabilize uma agenda de pesquisa e de formação de recursos humanos alinhada com aspectos de inclusão social. Investir em projetos - sociotécnicos - alicerçados nos princípios da economia solidária é contemplar os interesses de atores contra hegemônicos - com destaque aqui aos movimentos sociais, as comunidades locais organizadas e as organizações não-governamentais (ONGs) - e, por conseguinte, caminhar na direção de um desenvolvimento mais democrático, participativo e inclusivo (DAGNINO, 2004).

Articular uma TS é atuar e garantir o caráter sociotécnico do desenvolvimento. É, também, assumir a relação sempre simbiótica entre tecnologia e sociedade. Ao discutir o marco analítico conceitual da TS, Novaes e Dias (2009) reforçam o importante papel do desenvolvimento tecnológico como uma possível solução para exclusão social. Os autores veem nos empreendimentos solidários um importante lócus de desenvolvimento de tecnologias socialmente relevantes capazes de incorporar não apenas requisitos e finalidades de caráter técnicoeconômico, mas principalmente aspectos de natureza socioeconômica e ambiental fortemente ancoradas nas relações CTS.

\section{A história e o compromisso da UFFS com os movimentos sociais}

O perfil institucional da UFFS, bem como a sua missão, objetivos e área de atuação acadêmica, encontra forte vinculação com os movimentos sociais da Mesorregião da Grande Fronteira do Mercosul - daí resulta o nome Universidade Federal da Fronteira Sul -, e sua organização têm importante participação desses movimentos - representados em várias instâncias e, principalmente, no Conselho Estratégico Social (UFFS, 2012).

Nesse contexto, a UFFS "desenha o seu perfil como universidade multicampi, interestadual, pública, democrática, popular e socialmente comprometida com a realidade sociohistórica, econômica, política, ambiental e cultural da sua região de inserção" (UFFS, 2012, p. 9). Convém destacar que a Mesorregião da Grande Fronteira do Mercosul (Figura 1) compreende 396 municípios e cerca de 3.800.000 habitantes e, até a criação da UFFS (Lei 12.029/2009), sempre foi desassistida pelo poder público no tocante ao acesso à educação superior. Nesses municípios, em sua grande maioria de pequeno porte, cerca de $50 \%$ da população vive no meio rural (UFFS, 2012). 
Figura 1 - Área de abrangência da UFFS

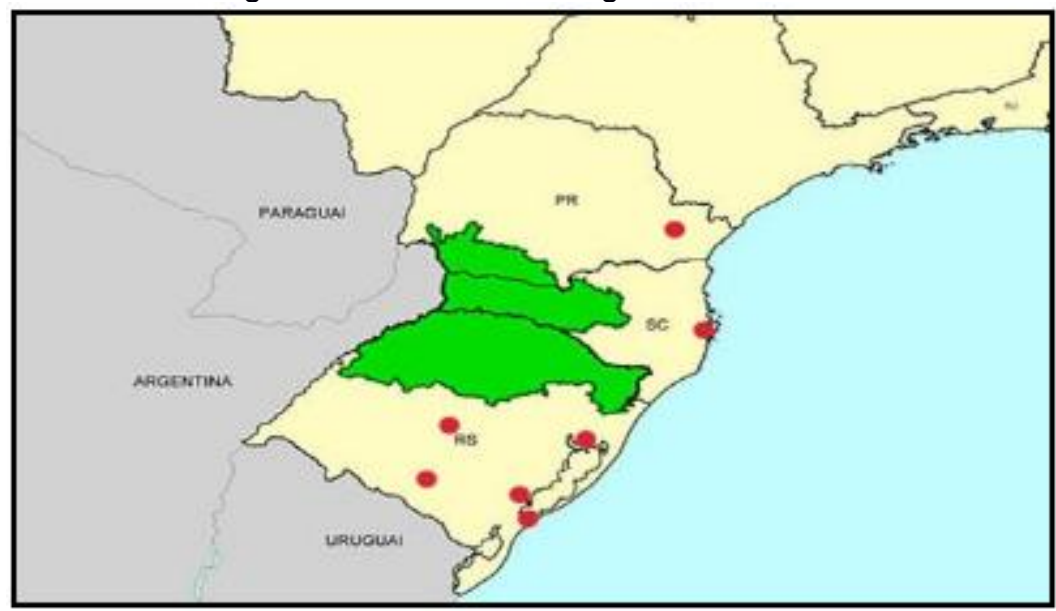

Fonte: UFFS (2012, p. 23)

A UFFS nasce, nesse território, com a missão de produzir conhecimento científico e inovação tecnológica como partes de um projeto de desenvolvimento que tenha como prioridade a formação humana, a inclusão social, a preservação das riquezas naturais e o combate às desigualdades regionais. Ao intentar contribuir com um desenvolvimento regional integrado, sustentável e solidário, a UFFS estimula a produção de conhecimentos e tecnologias que contribuam para a permanência dos jovens graduados na própria região.

Em seu Projeto Pedagógico Institucional (PPI) - documento integrante do Plano de Desenvolvimento Institucional (PDI) - a UFFS estabelece pressupostos filosóficos, políticos e acadêmicos, dentre os quais, pelo alinhamento com a proposta desse artigo, destacamos (UFFS, 2012):

a) Universidade democrática, autônoma, que respeite a pluralidade de pensamento e a diversidade cultural, com a garantia de espaços de participação dos diferentes sujeitos sociais;

b) Universidade que estabeleça dispositivos de combate às desigualdades sociais e regionais, incluindo condições de acesso e permanência no ensino superior, especialmente da população mais excluída do campo e da cidade;

c) Universidade que tenha na agricultura familiar um setor estruturador e dinamizador do processo de desenvolvimento;

d) Universidade que tenha como premissa a valorização e a superação da matriz produtiva existente;

e) Universidade de qualidade comprometida com a formação de cidadãos conscientes e comprometidos com o desenvolvimento sustentável e solidário da região sul do país.

Tais pressupostos, construídos historicamente num processo que se inicia oficialmente no ano de 2005 - com intensa participação de diferentes movimentos sociais dos três estados - e culmina em 2009, direcionam a definição dos cursos que foram implantados nos campi de Chapecó/SC, Cerro Largo/RS, Erechim/RS, Realeza/PR, Laranjeiras do Sul/PR e mais tarde no campus de Passo Fundo/RS. Especificamente sobre o eixo do desenvolvimento 


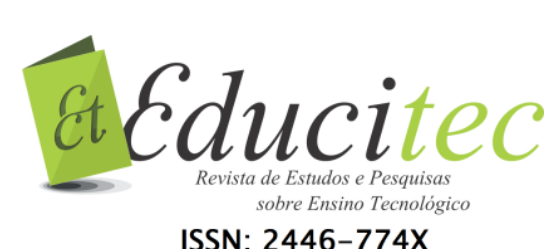

ISSN: $2446-774 X$

regional cada campus da instituição oferece um conjunto de cursos de Bacharelado com vistas ao atendimento das demandas específicas de desenvolvimento de cada região.

Sendo assim, os cursos de Engenharia Ambiental e Sanitária dos campi Chapecó, Cerro Largo e Erechim e Engenharia de Alimentos e Engenharia de Aquicultura, ambos ofertados no campus Laranjeiras do Sul, surgem das necessidades específicas de cada entorno onde se situam. Necessidades que dizem respeito tanto as soluções para problemas gerados pela atividade agrícola e agroindustrial tanto ao desenvolvimento de soluções tecnológicas para uma nova dinâmica produtiva da região.

Nesse ponto convém sintetizar a relação entre o cenário até aqui descrito de acordo com três importantes pontos do perfil institucional da UFFS: a vinculação com movimentos sociais desde sua idealização, criação e processo de consolidação; a marca institucional popular amplamente sublinhada nos documentos e meios de divulgação da universidade; e por fim, o compromisso com o desenvolvimento regional integrado, sustentável e solidário.

Buscando aproximações e articulações dos elementos balizadores da Universidade com os cursos de Engenharia oferecidos, já é possível apontar substanciais possibilidades de atuação em termos de TS. Se a proposta da universidade é a produção de conhecimento científico e de inovação tecnológica que priorizem a formação humana, a inclusão social e a atenuação das desigualdades, os empreendimentos solidários surgem como uma alternativa em estreito alinhamento com essa diretriz. Basta saber de que forma os Projetos Pedagógicos de Curso (PPCs) contemplam tais intencionalidades e promovem o desenvolvimento de tecnologias no âmbito dos empreendimentos solidários.

Também, destacamos nesse aspecto a origem dos estudantes da UFFS. Desde sua criação até o ano de 2012 o processo seletivo foi composto pela nota do Exame Nacional do Ensino Médio (ENEM) acrescido do fator escola pública, o qual consistia numa bonificação de $10 \%$ para cada ano do ensino médio cursado em escola pública. Isso garantiu que mais de $90 \%$ dos ingressantes nos três primeiros anos da instituição tivessem cursado os 3 anos do ensino médio em escola pública (UFFS, 2012). Tem-se aí um importante elemento de inclusão social.

Esse alto índice permanece até os dias atuais. No entanto, a partir de $2013 \mathrm{em}$ "obediência ao marco legal do Estado Brasileiro (especialmente a Lei $\mathrm{n}-12.711 / 2012$, o Decreto $\mathrm{n}^{\circ} \mathbf{7 . 8 2 4 / 2 0 1 2}$ e a Portaria Normativa MEC $\mathrm{n}^{\circ}$ $18 / 2012$ )" a UFFS formulou um modelo de ingresso mais detalhado, com entrada via Sistema de Seleção Unificada (SISU), contemplando percentuais de vagas para os que cursaram integralmente o ensino médio em escola pública, para os que cursaram parcialmente e para os que denomina de ampla concorrência (Tabela 1). A resolução № 8/2016/CONSUNI/CGAE (Conselho Universitário/Câmara de Graduação e Assuntos Estudantis), atualiza e explicita detalhadamente a política de ingresso, inclusive considerando o fator financeiro - renda bruta per capita da família - e cotas raciais - pretos, pardos e indígenas (UFFS, 2012, p. 41; UFFS, 2016b). 


\section{Eteducitec \\ ISSN: 2446-774X}

\begin{tabular}{c|c|c|c}
\hline \multicolumn{4}{c}{ Tabela 1 - Distribuição das vagas para ingresso na UFFS } \\
\hline Estado & $\begin{array}{c}\text { Integralmente em } \\
\text { Escola Pública }\end{array}$ & $\begin{array}{c}\text { Parcialmente em } \\
\text { Escola Pública }\end{array}$ & Ampla concorrência \\
\hline Paraná & $83 \%$ & $5 \%$ & $12 \%$ \\
\hline Santa Catarina & $82 \%$ & $5 \%$ & $13 \%$ \\
\hline Rio Grande do Sul & $85 \%$ & $5 \%$ & $10 \%$ \\
\hline
\end{tabular}

Fonte: UFFS (2012, p. 4)

Numa região de abrangência na qual a economia se estrutura em torno da produção agroindustrial e agropecuária em pequenas e médias propriedades, essa é mais uma característica que corrobora os argumentos a favor da TS.

\section{Os Projetos Pedagógicos dos cursos de Engenharia da UFFS}

Considerando que o projeto de Universidade desenhado pela UFFS apresenta profícuas possibilidades para o desenvolvimento de Tecnologias Sociais e, portanto, para um novo e diferente processo formativo para os cursos de Engenharia, neste item daremos destaque aos encontros e desencontros entre os ordenamentos institucionais e os PPCs dos cinco cursos de Engenharia ofertados pela instituição. Importante deixar claro que em nenhum documento $o$ termo Tecnologia Social aparece de forma literal. No entanto, como destacado em itens anteriores, a preocupação da UFFS com o desenvolvimento regional sustentável e solidário nos aponta para essa perspectiva. Devido à inexistência do termo Tecnologia Social, as unidades de análise contemplaram vinculações com os estudos CTS por entendermos que o enfoque social da tecnologia contempla, em boa medida, essa diferente concepção de desenvolvimento tecnológico. A análise documental dos PPCs nos levou a selecionar as seguintes categorias de análise: (1) Justificativa para criação do curso, (2) Perfil do egresso e objetivos do curso e (3) Organização curricular.

\section{Justificativa para criação dos cursos}

Sobre a justificativa para criação dos cursos, os textos partem de análises-macro do cenário brasileiro sobre a área de atuação a fim de evidenciar as proximidades com a Mesorregião da Fronteira Sul. Uma clara tentativa de contextualizar o curso e a formação num cenário mais amplo para, somente num segundo momento, chegar as especificidades da área de abrangência de cada campus.

Nesse sentido os três cursos de Engenharia Ambiental e Sanitária, destacam sua inserção na tentativa de contribuir com o diagnóstico e controle da poluição gerada pela atividade de criação em grande escala de animais - suínos e aves - na região. Também ressaltam a necessidades de melhorias significativas em relação ao saneamento básico das cidades que, nesse contexto, carecem de soluções quanto ao abastecimento de água, ao tratamento de efluentes e a disposição de resíduos sólidos (UFFS, 2013a; 2013b; 2013c). 


\section{Eteducitec}

ISSN: $2446-774 X$

Nesses documentos não há nenhum posicionamento claro a respeito da interação e do trabalho com associações cooperativas e, principalmente, com os movimentos sociais responsáveis pelas inúmeras ações que resultaram na criação da Universidade. Há sim uma intencionalidade em desenvolver soluções numa escala que não é macro. Considerando que os municípios de abrangência da UFFS são de pequeno porte e que grande parte da população reside na área rural, os cursos de Engenharia Ambiental e Sanitária assumem a responsabilidade - documental - de atuar nesse cenário. Percebe-se uma diferente concepção de solução tecnológica quando comparamos com Universidades e cursos de Engenharia localizados em grandes centros industrializados, por exemplo. No entanto, convém salientar que os projetos não atendem diretamente os preceitos da economia solidária e da autogestão, preconizados pela TS.

O curso de Engenharia de Alimentos contextualiza sua inserção destacando, do ponto de vista econômico, as atividades agropecuária, industrial e de serviços da região. Menciona a carência de agroindústrias e se posiciona frente a, ainda, incipiente produção das indústrias queijeiras e de abate de suínos e se propõe contribuir com o desenvolvimento nessa área (UFFS, 2016a).

Ao salientar que o curso objetiva formar profissionais capacitados para "desenvolver atividades voltadas para aplicação na indústria de alimentos e também efetuar pesquisas relacionadas ao acompanhamento, ao controle, à melhoria e à inovação em todos os processos envolvidos nas cadeias produtivas de insumos, embalagens, equipamentos e de alimentos", parece se embaralhar no que diz respeito ao foco nas pequenas propriedades e na realidade daquele entorno. Há um destaque importante à formação para o 'mercado' de trabalho e pelo registro de que o "curso se inspira em experiências de outros cursos já consolidados no Brasil e no exterior, com o intuito de formar profissionais que possam administrar a demanda por produtos de qualidade" (UFFS, 2016a, p. 18).

O curso de Engenharia de Aquicultura, por sua vez, destaca a distribuição fundiária com predominância de pequenas propriedades de exploração unifamiliar da região de abrangência do campus de Laranjeiras do Sul. Nesse sentido, faz menção ao assentamento de mais de 5 mil famílias de trabalhadores rurais sem-terra - 67 assentamentos da reforma agrária - e as mais 20 mil famílias de agricultores familiares, com o objetivo de destacar a capacidade de organização dos movimentos sociais e as iniciativas de trabalho em cooperativas (UFFS, 2010).

O curso justifica sua inserção na região devido à presença de cinco represas na bacia do rio Iguaçu, as quais apresentam grande potencial para piscicultura de larga escala em tanques-rede e, principalmente pela piscicultura de água doce no âmbito da produção familiar e cooperativa. Tal contextualização nos permite avaliar como uma importante aproximação com o desenvolvimento de TS no âmbito dos empreendimentos cooperativos. 


\section{Eteducitec}

ISSN: 2446-774X

\section{Perfil do egresso e objetivos do curso}

Sobre o perfil do egresso, percebe-se em todos os PPCs uma escrita pautada nas DCNs. A expressão 'atendimento as demandas da sociedade' aparece integral ou parcialmente referenciada quando o assunto é a proposição de soluções de Engenharia por parte dos profissionais formados pelo curso. Assim, percebemos textos como os de UFFS (2013c, p. 29): "O egresso deverá considerar, na resolução de problemas, seus aspectos ambientais, sociais e econômicos, a fim de que possa agir com clareza técnica e humanística em atendimento as demandas sociais".

No entanto, na medida em que se avança nas análises fica evidente uma exacerbada necessidade de destacar os atributos de uma sólida formação técnico-científica do futuro profissional. Assim, os termos 'projetar', 'aplicar', 'monitorar' e 'aperfeiçoar' não deixam claro sobre quais aspectos estão estruturados. Essa generalidade - que não deixa de indicar intenções - é percebida em todos os PPCs. Alguns, inclusive, acabam por exagerar na descrição, não de um perfil, mas de competências e habilidades - que somam mais de vinte itens - que o egresso deve assumir na vida profissional.

Entende-se, dessa forma, porque na contextualização do curso, os PPCs sempre partiram de um cenário global mais amplo para, somente, depois chegar na especificidade do contexto regional preconizado pelo PDI e pelo PPI. Isso está refletido no perfil do egresso, uma vez que a questão norteadora deixa de ser um profissional para o âmbito das pequenas propriedades e dos empreendimentos solidários e assume compromissos muito parecidos - senão iguais - aos de qualquer outro curso de Engenharia de instituições com perfis consideravelmente diferentes da UFFS.

Quando se busca contrapor o perfil do egresso com os objetivos do curso, a análise feita anteriormente é corroborada. Assim, o objetivo geral, está via de regra associado as questões técnicas e fortemente - quando não igualmente atrelado as competências e habilidades prescritas nas DCNs. A exceção que ocorre em UFFS (2013c) merece ser destacada pelo alinhamento com a temática desse artigo. No texto introdutório do item 'Objetivo' menciona-se:

Promover a formação de profissionais capacitados a utilizar os conhecimentos da engenharia ambiental para compreender e transformar o contexto sócio-politico do seu meio, entendendo as relações entre ciência, tecnologia e sociedade (UFFS, 2013c, p. 27, grifo nosso)

Afora isso, as questões do desenvolvimento regional vinculado as Tecnologias Sociais aparecem tangentes nos objetivos específicos. Assim, se projeta em (UFFS, 2016a, p. 25): "capacitar o profissional para a identificação da vocação da região a fim de promovê-la economicamente utilizando a sua potencialidade de produção"; e "possibilitar ao profissional formado propor políticas públicas, de acordo com a realidade e necessidade social". Este é o único PPC que menciona a profissão como definidora de políticas públicas. 
ISSN: $2446-774 X$

\section{Organização curricular}

Seguido orientações do PPI, os currículos dos cursos de Engenharia se organizam em torno de três domínios (UFFS, 2012):

a) Domínio Comum: composto por componentes curriculares que objetivam desenvolver em todos os estudantes da UFFS as habilidades e competências instrumentais consideradas fundamentais para o bom desempenho de qualquer profissional; corresponde a um mínimo de 420 horas e um máximo de 660 horas distribuídas por meio de disciplinas organizadas em dois eixos: (a1) Contextualização acadêmica: desenvolvimento de habilidades e competências de leitura, de interpretação e de produção em diferentes linguagens que auxiliem o estudante a se inserir de forma crítica no ambiente acadêmico e no contexto social e profissional; (a2) Formação crítico-social: compreensão crítica do mundo contemporâneo, contextualizando questões de ordem social, de relações de poder, de responsabilidade socioambiental e de organização sócio-político-econômica e cultural.

b) Domínio Conexo: corresponde aos componentes curriculares que se situam em espaço de interface interdisciplinar entre conjuntos de cursos ou, ainda, entre as grandes áreas do conhecimento.

c) Domínio específico: diz respeito à dimensão profissionalizante e, portanto, entendida como própria de cada curso.

Para os cursos de Engenharia, que historicamente são resistentes à inclusão de tópicos denominados pelas DCNs de 'Humanidades, Ciências Sociais e Cidadania', o eixo de Formação Crítico-Social do Domínio Comum indica profícuos tempos e espaços para discussões da natureza e das relações sociais da Engenharia. De acordo com UFFS (2012), tal eixo é composto pelos componentes curriculares de: (1) Introdução ao Pensamento Social, (2) Introdução à Filosofia, (3) Meio Ambiente, Economia e Sociedade, (4) Direitos e Cidadania e (4) História da Fronteira Sul.

Uma vez que o número de horas destinadas ao Domínio Comum é flexível, cada curso definiu, entre as disciplinas do Eixo de Formação Crítico Social, uma composição diferente, conforme Quadro 1.

Quadro 1 - Disciplinas do eixo de Formação Crítico Social dos cursos de Engenharia da UFFS (continua)

\begin{tabular}{|c|l|}
\hline Curso & $\begin{array}{c}\text { Disciplinas do Eixo de Formação Crítico } \\
\text { Social do Domínio Comum }\end{array}$ \\
\hline $\begin{array}{c}\text { Engenharia Ambiental e Sanitária - Cerro } \\
\text { Largo }\end{array}$ & $\begin{array}{l}\text { Introdução à Filosofia } \\
\text { Meio Ambiente, Economia e Sociedade } \\
\text { Direitos e Cidadania }\end{array}$ \\
\hline Engenharia Ambiental e Sanitária - Chapecó & $\begin{array}{l}\text { História Da Fronteira Sul } \\
\text { Introdução ao Pensamento Social } \\
\text { Meio Ambiente, Economia e Sociedade }\end{array}$ \\
\hline
\end{tabular}

Fonte: UFFS (2013a; 2013b, 2013c; 2016a; 2010) 


\section{alEducitec \\ ISSN: $2446-774 X$}

Quadro 1 - Disciplinas do eixo de Formação Crítico Social dos cursos de Engenharia da UFFS (conclusão)

\begin{tabular}{|c|l|}
\hline \multicolumn{1}{|c|}{ Curso } & $\begin{array}{l}\text { Disciplinas do Eixo de Formação Crítico } \\
\text { Social do Domínio Comum }\end{array}$ \\
\hline Engenharia Ambiental e Sanitária - Erechim & $\begin{array}{l}\text { Introdução à Filosofia } \\
\text { História da Fronteira Sul } \\
\text { Meio Ambiente, Economia e Sociedade }\end{array}$ \\
\hline Engenharia de Alimentos - Laranjeiras do Sul & $\begin{array}{l}\text { História da Fronteira Sul } \\
\text { Meio Ambiente, Economia e Sociedade } \\
\text { Direitos e cidadania }\end{array}$ \\
\hline Engenharia de Aquicultura - Laranjeiras do & $\begin{array}{l}\text { Introdução ao pensamento social } \\
\text { História da Fronteira Sul } \\
\text { Meio Ambiente, Economia e Sociedade } \\
\text { Fundamentos da Crítica Social } \\
\text { Direitos e cidadania }\end{array}$ \\
\hline
\end{tabular}

Fonte: UFFS (2013a; 2013b, 2013c; 2016a; 2010)

Sempre em número de três - com exceção do curso de Engenharia de Aquicultura que, como mencionado, ainda opera com o PPC de 2010 -, as disciplinas do eixo Formação Crítico Social configuram um diferencial em termos de organização curricular dos cursos objetos dessa análise. A presença em todos os cursos da disciplina de 'Meio Ambiente, Economia e Sociedade' merece destaque. Como já mencionado, ela não faz vinculação direta com o tema TS, mas por discutir temas como Modos de produção e organização social, Modelos produtivos e sustentabilidade e Experiências produtivas alternativas, se constitui como um importante tempo e espaço para discussões sobre o caráter sociotécnico da profissão.

No entanto, é importante esclarecer que tais disciplinas não são ministradas por professores engenheiros. Portanto, fica difícil avaliar as aproximações que os docentes, que não tem a tecnologia como objeto de estudo, conseguem articular com os estudantes de Engenharia. Retomamos aqui a discussão feita por Fraga, Novaes e Dagnino (2010), Bazzo (2014) e Lisingen (2015) que são contundentes ao afirmar que não basta acrescentar ao currículo dos cursos de Engenharia disciplinas da área de Humanidades. A problemática da falta de equilíbrio entre questões técnicas e aspectos sociais na formação em Engenharia tem raízes fortemente atreladas aos aspectos epistemológicos acerca da tecnologia e, portanto, os professores engenheiros têm papel fundamental na mudança de concepção que estamos discutindo no presente artigo.

Com relação ao Domínio Conexo, somente o curso de Engenharia de Aquicultura oferece disciplinas que apresentam vinculação direta com as discussões em torno da TS. Os conteúdos de 'Teoria Cooperativista l' fomentam o debate acerca economia solidária, da cooperação e da autogestão. A disciplina de 'Responsabilidade Sócio-Ambiental' por sua vez, problematiza a formação do profissional de Engenharia no âmbito da responsabilidade social.

Por fim, ao analisar as disciplinas de Domínio Específico percebemos que a relação da Engenharia com a Sociedade não configura nenhum eixo específico de formação. Essa questão é posta, nesse ponto, a fim de problematizar o que 


\section{alducitec \\ ISSN: 2446-774X}

já identificamos anteriormente: mesmo existindo um eixo de formação Críticosocial vinculado ao Domínio Comum - o que já constitui um positivo diferencial para os cursos analisados -, os professores engenheiros não assumem, nesse olhar macro sobre as matrizes curriculares, responsabilidade e participação direta nas discussões sobre a imbricada relação CTS. Não é objeto de análise nesse artigo, mas a investigação das práticas dos professores poderia corroborar essa tese ou mostrar um cenário mais promissor em torno do desenvolvimento de Tecnologias Sociais.

\section{Sobre (in)coerências: o peso da formação dos formadores}

Ao fazermos os fechamentos desse artigo queremos tornar presente o trocadilho feito com a palavra (in)coerência. Se por um lado, como estudiosos da imbricada relação entre a tecnologia e a sociedade, enxergamos nesse lócus de estudo uma expressiva coerência entre o projeto de Universidade Popular e o desenvolvimento de Tecnologias Sociais, por outro as análises dos projetos pedagógicos dos cursos de Engenharia nos mostraram consideráveis incoerências frente a essa perspectiva.

Ao longo do percurso de investigação tivemos a impressão de que na medida em que partíamos das análises macro - a Universidade - para um olhar mais apurado no micro - os cursos - as concepções, as diretrizes e as possibilidades de um desenvolvimento solidário comprometido com os movimentos sociais, com as pequenas propriedades, e com a geração de uma nova dinâmica regional se diluíam nas páginas dos documentos. Isso nos revela que, apesar da mudança substancial de contexto, os cursos de Engenharia tendem a se estruturar de forma tradicional.

Não podemos deixar de valorizar uma dinâmica curricular que é, notadamente, diferenciada. Trabalhar com a lógica de três domínios - comum, conexo e específico - é valorizar a pluralidade de saberes. Além disso é uma tentativa clara de descompartimentar o conhecimento e abrir espaços para discussões que extrapolem o puramente técnico da profissão. Se queremos caminhar para o desenvolvimento de Tecnologias Sociais precisamos avançar, certamente, em práticas multidisciplinares.

Também é preciso mencionar que encontramos e apontamos ao longo desse texto importantes vinculações entre os projetos dos cursos de Engenharia e a temática da TS. Isso se dá por meio da consciência de que as soluções desenvolvidas no espaço acadêmico precisam dialogar com a comunidade regional e com os movimentos sociais - MST, como aparece no documento da Engenharia de Aquicultura de Laranjeiras do Sul -. Também algumas disciplinas, notadamente diferentes das ofertadas nos tradicionais cursos de Engenharia, se constituem como importantes instrumentos na problematização de temas de relevância social no âmbito das práticas profissionais.

Nos fica a certeza de que a coerência entre a universidade popular e o desenvolvimento de TS requer, por parte dos professores engenheiros, mudanças, principalmente, de ordem epistemológica. Afinal, são os professores 


\section{aleducitec \\ ISSN: 2446-774X}

formadores que escrevem e concebem os projetos pedagógicos dos cursos. São eles que dão o tom da projeção. São eles que fazem, também, a materialização desse projeto.

Temos no horizonte uma futura investigação: analisar as práticas de ensino, pesquisa e extensão dos professores para entender melhor como se dá a dinâmica formativa nesses espaços. Avaliar o cenário como um todo nos ajudará na proposição de orientações que auxiliem na superação da dicotomia entre desenvolvimento tecnológico e desenvolvimento social.

\section{Referências}

BAZZO, Walter Antonio. Ciência, tecnologia e sociedade: e o contexto da educação tecnológica, 1998, 267p, Tese (Doutorado em Educação) Universidade Federal de Santa Catarina, Florianópolis, 1998.

BAZZO, Walter Antonio. Ciência, Tecnologia e Sociedade e o contexto da educação tecnológica. 4. ed. rev. Florianópolis: Ed. da UFSC, 2014.

CARLETTO, Marcia Regina. Avaliação de impacto tecnológico: alternativas e desafios para a educação crítica em engenharia, 2009, 283p, Tese (Doutorado em Educação Científica e Tecnológica) - Universidade Federal de Santa Catarina, Florianópolis, 2008.

DAGNINO, Renato Peixoto. A Tecnologia Social e seus desafios. In: LASSANCE Jr, Antonio E. et. al. (Org). Tecnologia Social: uma estratégia para o desenvolvimento. Rio de Janeiro, Fundação Banco do Brasil, 2004. p. 187-210.

DAGNINO, Renato Peixoto. Em direção a uma teoria crítica da tecnologia. In: DAGNINO, Renato Peixoto (Org). Tecnologia social: ferramenta para construir outra sociedade. Campinas: IG/UNICAMP, 2009. p. 73-112.

FRAGA, Laís Silveira. O curso de Graduação da Faculdade de Engenharia de Alimentos da UNICAMP: uma análise a partir da Educação em Ciência, Tecnologia e Sociedade, 2007, 86p, Dissertação (Mestrado em Política Científica e Tecnológica) - Universidade Estadual de Campinas, Campinas, 2007.

FRAGA, Lais Silveira. NOVAES, Henrique T. DAGNINO, Renato Peixoto. Educação em Ciência, tecnologia e sociedade para as engenharias: obstáculos e propostas. In: DAGNINO, Renato (Org.). Estudos sociais da ciência e tecnologia e política de ciência e tecnologia: abordagens alternativas para uma nova América Latina. Campina Grande. Eduepb, 2010. p 213-234.

JACINSKI. Edson. Sentidos das interações entre tecnologia e sociedade na formação de engenheiros: limites e possibilidades para repensar a educação tecnológica. 2012, 363p, Tese (Doutorado em Educação Científica e Tecnológica) - Universidade Federal de Santa Catarina, Florianópolis, 2012.

LINSINGEN, Irlan. Engenharia, tecnologia e sociedade: novas perspectivas para uma formação, 2002, 210p, Tese (Doutorado em Educação) - Universidade Federal de Santa Catarina, Florianópolis, 2002. 


\section{Edecitec \\ ISSN: 2446-774X}

LINSINGEN, Irlan. Perspectivas curriculares CTS para o ensino de engenharia: uma proposta de formação universitária. Linhas Críticas (UnB), v. 21, p. 297 317, 2015.

MENESTRINA, Tatiana Comiotto. Concepção de Ciência, Tecnologia e Sociedade na formação de engenheiros: um estudo de caso das engenharias da UDESC Joinville. 2008, 237p, Tese (Doutorado em Educação Cientifica e Tecnológica) - Universidade Federal de Santa Catarina, Florianópolis, 2008.

NOVAES, Henrique T.; DIAS, Rafael. Contribuições ao Marco AnalíticoConceitual da Tecnologia Social. In: DAGNINO, Renato Peixoto (Org). Tecnologia social: ferramenta para construir outra sociedade. Campinas: IG/UNICAMP, 2009. p. 17-53.

NÓVOA, Antonio. Entrevista. (2017). Disponível em: <http://http://www.cartaeducacao.com.br/reportagens/se-fosse-brasileiroestaria-indignado-com-a-situacao-da-educacao/>. Acesso em: 30 ago. 2017.

POSTMAN, Neil; WEINGARTNER, Charles. Contestação: nova fórmula de ensino. Rio e Janeiro: Editora Expressão e Cultura, 1971.

UFFS. Projeto Pedagógico do curso de graduação em Engenharia de Aquicultura - bacharelado. Laranjeiras do Sul: 2010. Disponível em: $<$ https://www.uffs.edu.br/atos-normativos/ppc/cceaqls/2016-0002>. Acesso em: 13 set. 2017.

UFFS. PDI: Plano de Desenvolvimento Institucional 2012-2016. Chapecó: UFFS, $2012 . \quad$ Disponível em: <https://www.uffs.edu.br/institucional/a_uffs/a_instituicao/plano_de_desenvolvi mento_institucional>. Acesso em: 10 ago. 2017.

UFFS. Projeto Pedagógico do curso de graduação em Engenharia Ambiental bacharelado, campus Cerro Largo. Cerro Largo: 2013a. Disponível em: $<$ https://www.uffs.edu.br/campi/cerro-largo/cursos/graduacao/engenhariaambiental/documentos>. Acesso em: 13 set. 2017.

UFFS. Projeto Pedagógico do curso de graduação em Engenharia Ambiental bacharelado. Chapecó: 2013b. Disponível em: $<$ https://www.uffs.edu.br/campi/chapeco/cursos/graduacao/engenhariaambiental/documentos>. Acesso em: 13 set. 2017.

UFFS. Projeto Pedagógico do curso de graduação em Engenharia Ambiental bacharelado. Erechim: 2013c. Disponível em: <https://www.uffs.edu.br/campi/erechim/cursos/graduacao/engenhariaambiental/documentos>. Acesso em: 13 set. 2017.

UFFS. Projeto Pedagógico do curso de graduação em Engenharia de alimentos - bacharelado. Laranjeiras do Sul: 2016a. Disponível em: $<$ https://www.uffs.edu.br/atos-normativos/ppc/ccealls/2016-0002>. Acesso em: 13 set. 2017.

UFFS. RESOLUÇÃO № 8/2016 - CONSUNI/CGAE: Altera a Resolução ํo 006/2012- CONSUNI/CGRAD, que aprova o modelo de implantação da reserva de vagas para a política de ingresso nos cursos de graduação da UFFS. 


\section{Et Educitec}

ISSN: $2446-774 X$

Chapecó: 2016b. Disponível em: <https://www.uffs.edu.br/atosnormativos/resolucao/consunicgae/2016-0008 >. Acesso em 10 ago. 2017.

WINNER, Langdon. La Ballena y el Reactor: una búsqueda de los limites em la era de la alta tecnología. Barcelona: Gedisa editorial, 1987.

Submetido em 23/09/2018.

Aceito em 27/05/2019.

cc) (i) 